\title{
Mass spectrometric investigation of the ionic species in a dielectric barrier discharge operating in helium-water vapour mixtures
}

\author{
Z Abd-Allah ${ }^{1}$, D A G Sawtell ${ }^{2}$, K McKay ${ }^{1}$, G T West ${ }^{2}$, P J Kelly ${ }^{2}$ and J W Bradley ${ }^{1}$ \\ ${ }^{1}$ Dept. of Electrical Engineering and Electronics, The University of Liverpool, Brownlow Hill, \\ Liverpool, L69 3GJ, UK \\ ${ }^{2}$ Surface Engineering Group, Manchester Metropolitan University, Manchester, M1 5GD, UK
}

E-mail: jbradley@liverpool.ac.uk

\begin{abstract}
:
Using advanced mass spectrometry the chemistry of ionic species present in an atmospheric pressure parallel plate dielectric barrier discharge (DBD) with a single dielectric on the powered electrode have been identified. The discharge was driven in helium with controllable concentrations of water vapour using an excitation frequency of $10 \mathrm{kHz}$ and an applied voltage of $1.2 \mathrm{kV}$. Both negative and positive ions were identified and their relative intensity determined with variation of water concentration in the discharge, inter-electrode spacing, gas residence time and nominal applied power. The most abundant negative ions were of the family $\mathrm{OH}^{-}\left(\mathrm{H}_{2} \mathrm{O}\right)_{n}$, while the positive ions were dominated by those of the form $\mathrm{H}^{+}\left(\mathrm{H}_{2} \mathrm{O}\right)_{n}$, with n up to 9 in both cases. Negative and positive ions responded in a similar way to changes in the operating parameters, with the particular response depending on the ion mass. Increasing the inter-electrode spacing and the water concentration in the discharge led to an increase in the intensity of large mass ionic water clusters. However, increasing the residence time of the species in the plasma region and increasing the applied power resulted in fragmentation of large water clusters to produce smaller ions.
\end{abstract}

\section{Introduction}

Dielectric barrier discharge (DBD) plasma sources are used in numerous applications including areas such as ozone generation [1-3], plasma medicine [4-6], pollution control [7-9] and surface modification [10-12]. Dielectric barrier discharges are low temperature non-equilibrium plasmas typically obtained between two parallel electrodes, one or both of which is covered with a dielectric barrier, separated by a gap ranging from $0.1 \mathrm{~mm}$ to several centimetres $[1,10,13]$. The area of the electrodes can range from several square millimetres and up to square meters $[10,14,15]$. DBD's are typically excited by alternating high voltages with frequencies ranging from $50 \mathrm{~Hz}$ up to $10 \mathrm{MHz}$, and are known to operate in either 
homogenous (diffusive) mode or filamentary mode [10, 13, 16-18]. In the latter case microdischarges with a radius of about $100 \mu \mathrm{m}$ are formed $[10,12,19,20]$. The majority of DBD sources are operated in near ambient conditions, where moisture is an important feature of the process. It is therefore important to understand the effect water vapour can have on the plasma chemistry. The discharge properties of DBD's have been studied previously using a variety of diagnostic methods such as optical emission, Fourier Transform Infra-red (FTIR), infra-red laser absorption and electrical diagnostics [14, 21]. To date, however, very little detailed analysis of the ion chemistry produced in $\mathrm{kHz}$ DBDs has been conducted. In contrast, there have been numerous studies concerning the ionic species present in capacitively coupled discharges at low-pressure (e.g. at few $10^{-1} \mathrm{~Pa}$ ) [22-24]. Most mass spectrometric studies of atmosphericpressure plasmas have concentrated on jet plasma plumes to sample the effluent $[25,26]$ rather than insitu (between the electrodes) of the active plasma region. Bruggerman et.al [27] reported the first use of mass spectrometry to measure the ionic species produced in parallel plate atmospheric pressure radio frequency glow discharge using various helium and water mixtures. Due to the discharge operating in the $\mathrm{RF}$ regime no dielectric barrier was required to prevent the glow-to-arc transition. As far as we know, there are no reported studies of in-situ mass spectrometric measurements of ionic species generated in audio frequency, atmospheric pressure DBD plasma. Nor is there a detailed investigation of the effect of operating parameters on the generation of ionic species and their subsequent chemistry.

Here, we present the first mass spectrometric study of negative and positive ions produced in a $\mathrm{kHz}$ dielectric barrier discharge under various operating conditions. One dielectric barrier was present on the driven electrode and the mass spectrometer extraction orifice plate acted as the ground electrode allowing for in-situ measurements of the species arriving at the boundary. The filamentary discharge obtained in this DBD operated in a controlled environment where water vapour was added to the gas at fixed concentrations. To determine the effect that changing the operating parameters had on the discharge chemistry, the water vapour present within the discharge was varied from 0.055 to $0.5 \%$ (by volume) by increasing the helium flow into the bubbler and the inter-electrode spacing was varied from $0.25 \mathrm{~mm}$ to $2 \mathrm{~mm}$. In addition to water concentration and inter-electrode spacing the gas residence time and the applied power were also varied.

\section{Experimental set-up}

The atmospheric pressure discharge was generated in a parallel plate reactor, consisting of two metal electrodes with a dielectric disc of alumina ( $0.5 \mathrm{~mm}$ thick, $99.6 \%$ alumina and dielectric constant 9.9) covering the driven electrode. The spectrometer was incorporated into the reactor as the ground electrode while the driven electrode was made of copper with a $2 \mathrm{~cm}$ diameter. The reactor was encased in a gas filled chamber of helium and water vapour; this allowed us to control the environmental condition present around the electrodes. The main carrier gas used in this case was helium (purity of 99.995\%). Part of the total helium flow was diverted to a water filled bubbler at room temperature to obtain the required concentration of water entering the plasma reactor. The helium flow into the bubbler was fully submerged 
in the water to insure a good saturation of the helium with water vapour. This flow was controlled using MKS mass flow controllers. To control the amount of water vapour in the discharge, the required flow rate was calculated using the Antoine equation, Daltons law of partial pressure and mass balance equations. The main parameters affecting water vapour concentration are water temperature and helium flow rate. The error in the flow rate is less than $1 \%$, while a change of $\pm 1{ }^{\circ} \mathrm{C}$ in the water temperature results in an uncertainty of water vapour concentration of $\pm 6 \%$. The discharge was powered using a high voltage $(1.2 \mathrm{kV})$, sinusoidal $10 \mathrm{kHz}$ power source consisting of a digital function generator, driving a commercial audio amplifier. A purpose built voltage step-up transformer was connected to the output to generate the required high voltages. A 1000:1 Tektronix voltage probe and Pearson current monitor were used to characterize the discharge power, which was varied from $0.1 \mathrm{~W}$ to $0.7 \mathrm{~W}$. The average power delivered to the plasma reactor was calculated from the integral of the product of the time-dependent voltage and currents over one pulse duration, normalized by the repetition frequency, $f(10 \mathrm{kHz})$ namely, $P=f \int_{0}^{T} V(t) \times I(t) d t$

Here $T$ is the pulse duration, $V(t)$ is the applied voltage and $I(t)$ is the input current $[8,28]$.

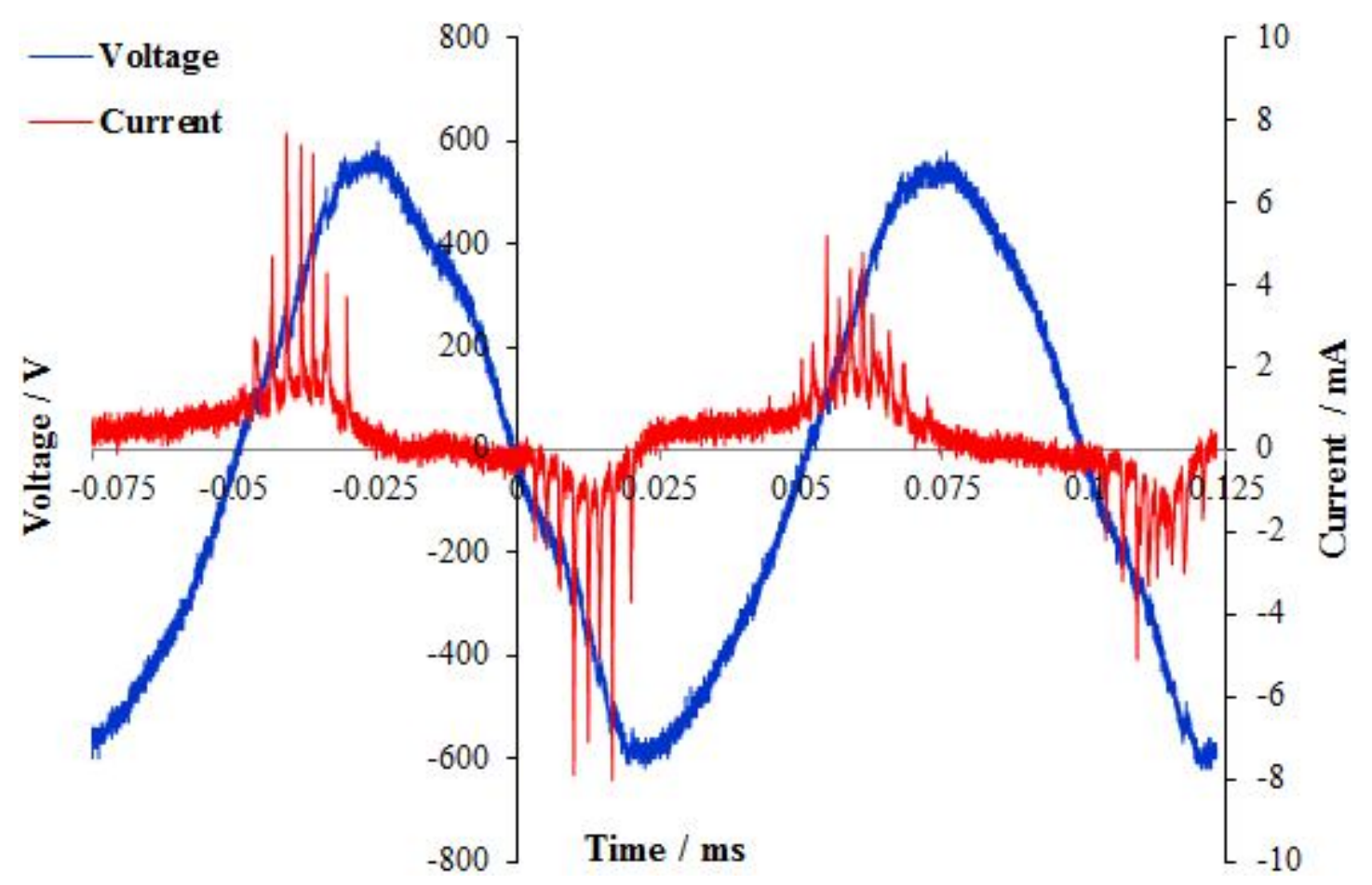

Figure 1. An example current and voltage waveforms. Water concentration of $0.3 \%$, total flow rate of 5 slm, electrodes gap $0.5 \mathrm{~mm}$ and frequency of $10 \mathrm{kHz}$ were used.

This simple calculation gives an upper limit of the consumed power at any applied voltage. Figure 1 for the measured current and voltage traces shows that about $20 \%$ of total current is in the form of displacement current, the remaining $80 \%$ of the total current constitutes the discharge current. The 
filamentary nature of the discharge can be seen, however poor oscilloscope resolution allow only a small fraction of the filaments to be displayed. Figure 2 shows a schematic of the experimental arrangement.

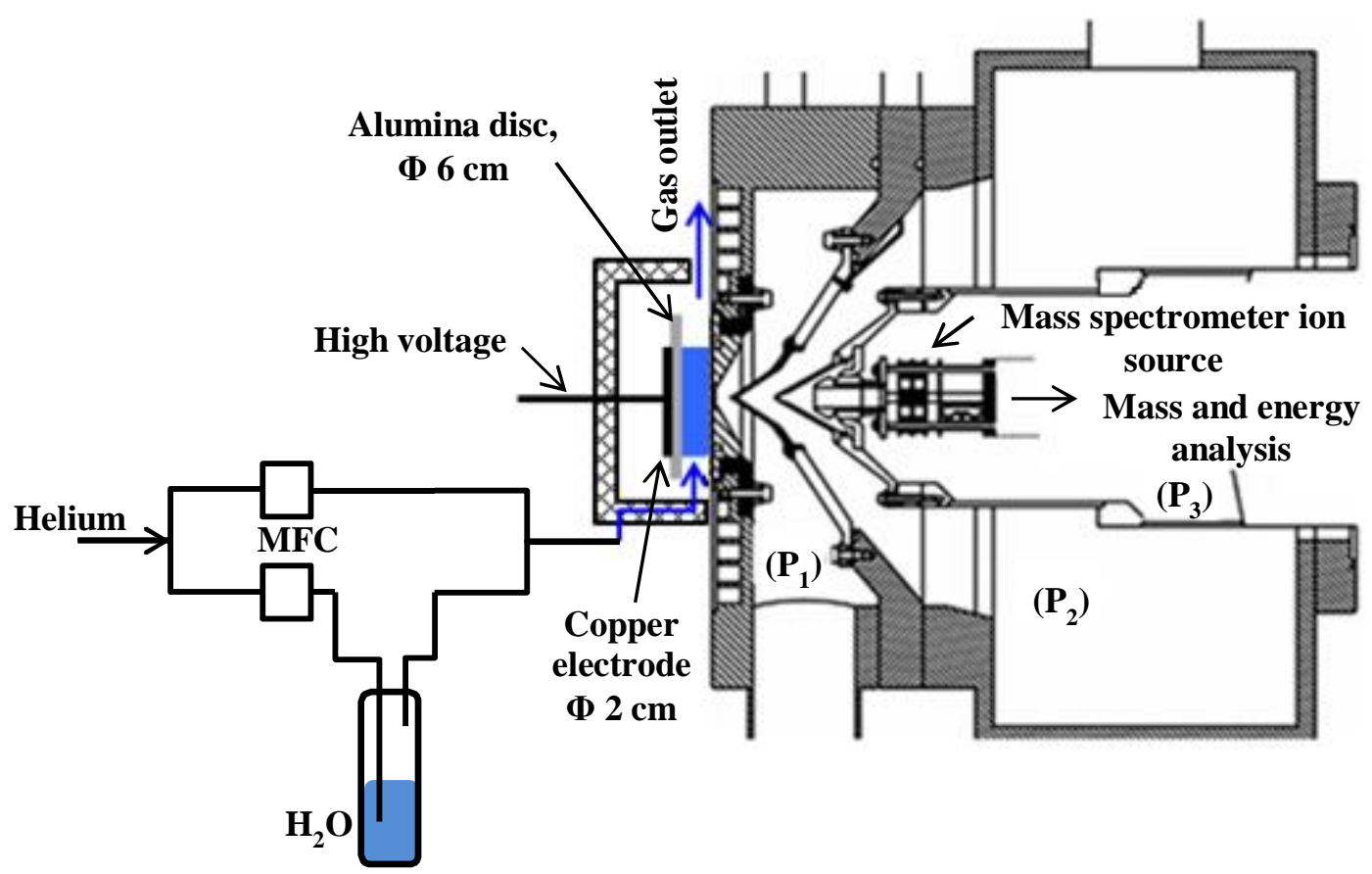

Figure 2. Experimental set up showing the DBD-MS arrangement.

The mass spectrometer employed here was a quadrupole-based molecular beam mass spectrometer, HPR60, manufactured by HIDEN Analytical Ltd. The instrument consists of a three stage differentially pumped inlet system separated by aligned skimmer cones and turbomolecular pumps. The pressures in these stages were as follow: $\mathrm{P}_{1}=3.3 \times 10^{-1} \mathrm{~Pa}, \mathrm{P}_{2}=9.8 \times 10^{-3}$ and $\mathrm{P}_{3}=7.7 \times 10^{-5} \mathrm{~Pa}$. The HPR-60 has two operational modes, one to detect neutral species (residual gas analyser, RGA, mode) and the other to detect positive and negative ions (secondary ion mass spectroscopy, SIMS, mode). For this study, ions up to $200 \mathrm{amu}$ were detected with a resolution of $0.2 \mathrm{amu}$. Auto tuning for the mass spectrometer analyser components was carried out in a gas mixture of helium and $0.15 \%$ of water vapour. This was performed for neutrals, negative and positive ions before commencing the experiments. The Auto tuning program chooses the most abundant ion in the discharge and tunes the analyser to get the best signal intensity. An extraction cone with $25 \mu \mathrm{m}$ orifice was used in this experiment; this small aperture prevented penetration of the electric field from the first electrode behind the extraction cone into the discharge region as well as providing a continuous sheath across the orifice so preventing plasma penetration into the instrument itself. This reduced the chances of internal ion production and unwanted ion acceleration. The effective sheath thickness for similar plasma sources is in the range of $100 \mu \mathrm{m}$ [27].

\section{Results and discussion}

In the following sub-sections we will examine the influence of water concentration, residence time, interelectrode spacing and applied power on the intensity of ionic species in the discharge. Where results are 
presented as a function of relative yield $(Y(\%))$, relative yield was calculated by dividing the count intensity of a specific ion $(i)$ on the total count intensity of all the detected ions $\left(Y(\%)=Y_{i} \times 100 / \sum_{\mathrm{i}} Y_{i}\right)$. To reduce error in the relative yield, ten separate scans of each spectrum were obtained and averaged. The standard deviation of the relative yield for any of these species was less than $1 \%$ and so can be considered marginal.

\subsection{Influence of water concentration on negative and positive ions composition}

Mass spectrometry measurements using RGA and SIMS modes were carried out to characterize the neutral and ionic species in the gas mixture, respectively. Neutrals were measured before initiating the plasma, while ionic species were measured in the active plasma region. The predominant neutral species in the gas feed shown in figure 3 were helium and water. Trace amounts of nitrogen, oxygen and carbon dioxide were also detected indicating the presence of a small leak from the surrounding atmosphere into the environment system or possible impurities in the helium gas cylinder.

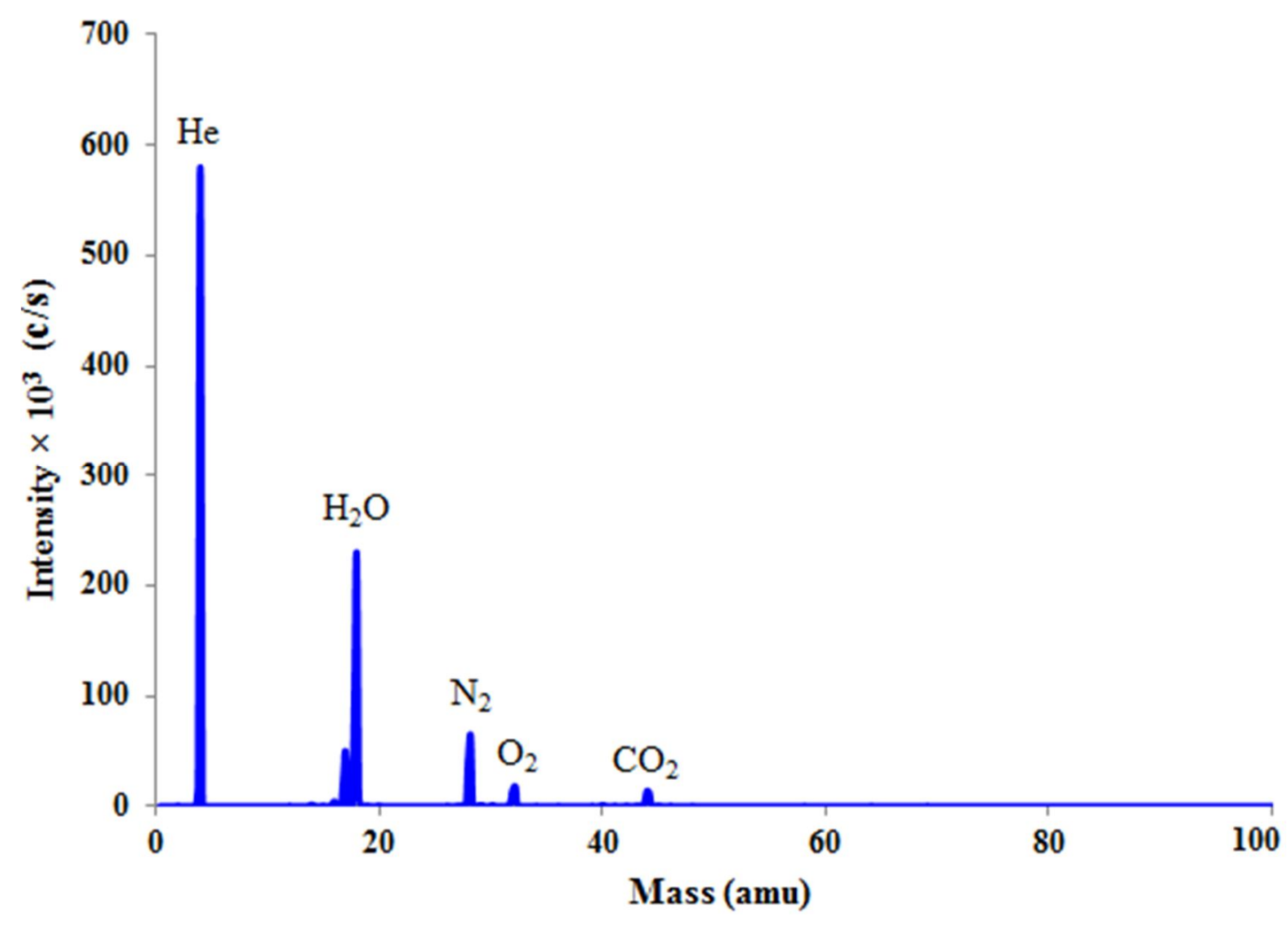

Figure 3. Mass spectrum for neutrals present in helium and $0.3 \%$ (by volume) water vapour.

Figures 4 and 5 show negative and positive ions produced with approximately 0.055 and $0.3 \%$ (by volume) of water present in the discharge respectively. No ions were detected above $200 \mathrm{amu}$. Here the inter-electrode spacing was fixed to $0.5 \mathrm{~mm}$ and the applied power was kept constant at $0.3 \mathrm{~W}$. The total gas flow rate to the reactor is $5 \mathrm{slm}$ corresponding to a residence time of $1.7 \mathrm{~ms}$. For all the water concentrations studied, the main negative ions detected were $\mathrm{O}^{-}, \mathrm{OH}^{-}, \mathrm{NO}_{2}^{-}, \mathrm{O}^{-}\left(\mathrm{H}_{2} \mathrm{O}\right)_{n}$ and 
$\mathrm{OH}^{-}\left(\mathrm{H}_{2} \mathrm{O}\right)_{n}$. For a water vapour concentration of $0.055 \%$, the dominant negative ions were $\mathrm{OH}^{-}$and $\mathrm{OH}^{-}\left(\mathrm{H}_{2} \mathrm{O}\right)_{3}$. Increasing the water vapour concentration resulted in increasing numbers of water cluster ions being detected. As the water vapour concentration was increased $(\geq 0.3 \%)$ the main ion detected was $\mathrm{OH}^{-}\left(\mathrm{H}_{2} \mathrm{O}\right)_{6}$. Nitrogen dioxide ions and it's hydrated clusters $\left(\mathrm{NO}_{2}^{-}\right.$and $\left.\mathrm{NO}_{2}^{-}\left(\mathrm{H}_{2} \mathrm{O}\right)_{n}\right)$ were also detected in the plasma, this resulted from the presence of nitrogen and oxygen impurities in the system. The most abundant positive ions measured were $\mathrm{H}^{+}\left(\mathrm{H}_{2} \mathrm{O}\right)_{n}$. Small traces of $\mathrm{H}_{2} \mathrm{O}^{+}, \mathrm{O}_{2}^{+}, \mathrm{N}_{2}^{+}$and $\mathrm{H}_{3}^{+}\left(\mathrm{H}_{2} \mathrm{O}\right)_{n}$ were also detected. The dominant positive ion was $\mathrm{H}^{+}\left(\mathrm{H}_{2} \mathrm{O}\right)_{3}$ when the water concentration was low. As the water concentration increased the dominance shifted towards larger water clusters, in this case $\mathrm{H}^{+}\left(\mathrm{H}_{2} \mathrm{O}\right)_{5}$. Similar results were reported by Bruggeman et al. [27] for the effect of water concentration on positive and negative ion production. It should be noted that no helium ions were detected; this is thought to be due to the presence of water vapour in the system. Similar observations were made by Bruggeman et al. [27] and Martens et al. [29]. Martens et al. reported that the presence of any impurity above $1 \mathrm{ppm}$ in a helium discharge leads to the domination of these impurity ions over helium ions.

Negative ions are thought to be produced through two main pathways: dissociative electron attachment and ion-molecule attachment processes [25, 30]. The main reactions leading to the formation of the detected negative ions are:

1- Dissociative electron attachment [31-33]:

$$
\begin{array}{ll}
e^{-}+\mathrm{H}_{2} \mathrm{O} \rightarrow \mathrm{OH}^{-}+\mathrm{H} & k_{l}=f\left(T_{e}\right) \\
e^{-}+\mathrm{H}_{2} \mathrm{O} \rightarrow \mathrm{O}^{-}+\mathrm{H}_{2} & k_{2}=f\left(T_{e}\right)
\end{array}
$$

2- Ion-molecule reaction process [33, 34]:

$$
\begin{array}{lc}
\mathrm{OH}^{-}+\mathrm{H}_{2} \mathrm{O}+\mathrm{M} \rightarrow \mathrm{OH}^{-}\left(\mathrm{H}_{2} \mathrm{O}\right)+\mathrm{M} & k_{3}=2.5 \times 10^{-28} \mathrm{~cm}^{6} \mathrm{~s}^{-1} \\
\mathrm{O}^{-}+\mathrm{H}_{2} \mathrm{O}+\mathrm{M} \rightarrow \mathrm{O}^{-}\left(\mathrm{H}_{2} \mathrm{O}\right)+M & k_{4}=1.3 \times 10^{-28} \mathrm{~cm}^{6} \mathrm{~s}^{-1} \\
\mathrm{OH}^{-}\left(\mathrm{H}_{2} \mathrm{O}\right)_{n}+\mathrm{H}_{2} \mathrm{O}+\mathrm{M} \rightarrow \mathrm{OH}^{-}\left(\mathrm{H}_{2} \mathrm{O}\right)_{n+1}+\mathrm{M} & n=, 12,3 . . k_{5} \sim 5 \times 10^{-28} \mathrm{~cm}^{6} \mathrm{~s}^{-1} \\
\mathrm{O}^{-}\left(\mathrm{H}_{2} \mathrm{O}\right)_{n}+\mathrm{H}_{2} \mathrm{O} \rightarrow \mathrm{OH}^{-}\left(\mathrm{H}_{2} \mathrm{O}\right)_{n}+\mathrm{OH} & \text { For } n=1, k_{6}>1 \times 10^{-11} \mathrm{~cm}^{3} \mathrm{~s}^{-1}
\end{array}
$$

Where $M$ represents any non-reactive species. Protonated water clusters are mainly formed via Penning ionization by helium metastables $\left(H e^{m}\right)$. Helium metastables have an energy of $19.8 \mathrm{eV}$, this is significantly higher than the energy required to ionize/dissociate water molecules [29-33, 35, 36].

$$
\begin{array}{ll}
e^{-}+\mathrm{He} \rightarrow e^{-}+\mathrm{He}^{m} & k_{7}=f\left(T_{e}\right) \\
\mathrm{He}^{m}+\mathrm{nH}_{2} \mathrm{O} \rightarrow \mathrm{H}^{+}\left(\mathrm{H}_{2} \mathrm{O}\right)_{n-1}+\mathrm{He}+\mathrm{OH}^{-} &
\end{array}
$$

Protonated water clusters are also formed via ion-molecule reactions after the formation of $\mathrm{H}_{2} \mathrm{O}^{+}$ ions $[33,37]$ as follow: 
$\mathrm{H}_{2} \mathrm{O}^{+}+n \mathrm{H}_{2} \mathrm{O} \rightarrow \mathrm{H}^{+}\left(\mathrm{H}_{2} \mathrm{O}\right)_{n}+\mathrm{OH} \quad$ For $n=1, k_{9}=1.8 \times 10^{-9} \mathrm{~cm}^{3} \mathrm{~s}^{-1}$

$\mathrm{H}^{+}\left(\mathrm{H}_{2} \mathrm{O}\right)_{n}+\mathrm{H}_{2} \mathrm{O}+\mathrm{M} \rightarrow \mathrm{H}^{+}\left(\mathrm{H}_{2} \mathrm{O}\right)_{n+1}+\mathrm{M} \quad$ For $n=1, k_{10}=6.65 \times 10^{-28} \mathrm{~cm}^{6} \mathrm{~s}^{-1}$

The positive ion, $\mathrm{H}_{2} \mathrm{O}^{+}$, is formed by water molecule reactions with positive ions such as $\mathrm{He}^{+}, \mathrm{O}^{+}, \mathrm{N}^{+}$ and $N_{2}{ }^{+}[33,37]$.

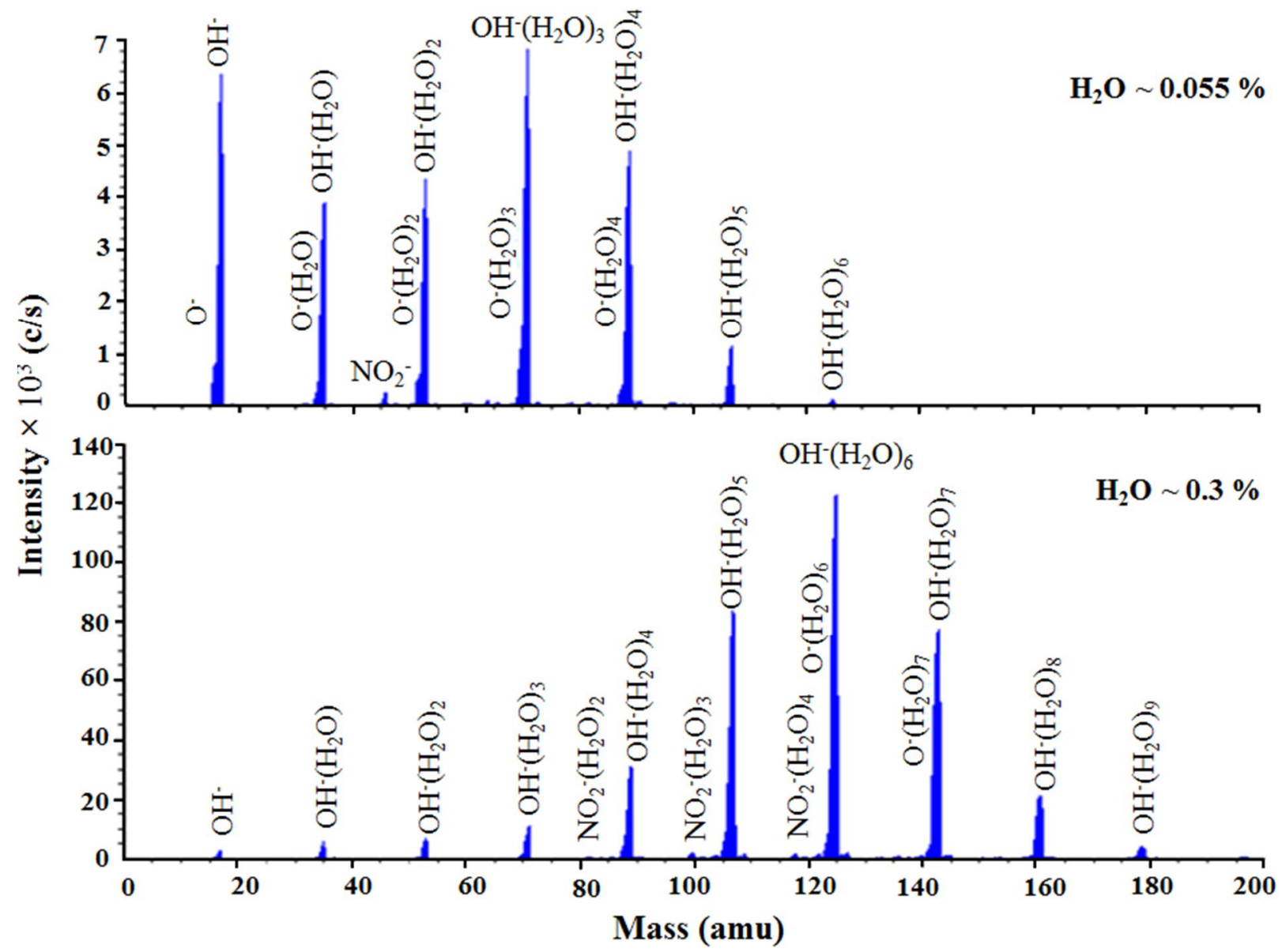

Figure 4. Negative ion mass spectra for two different water concentrations by volume $0.055 \%$ and 0.3 $\%$. Total flow rate of about $5 \mathrm{slm}$, applied power $0.3 \mathrm{~W}$, electrode separation $0.5 \mathrm{~mm}$, residence time $1.7 \mathrm{~ms}$ and frequency of $10 \mathrm{kHz}$ were used. 


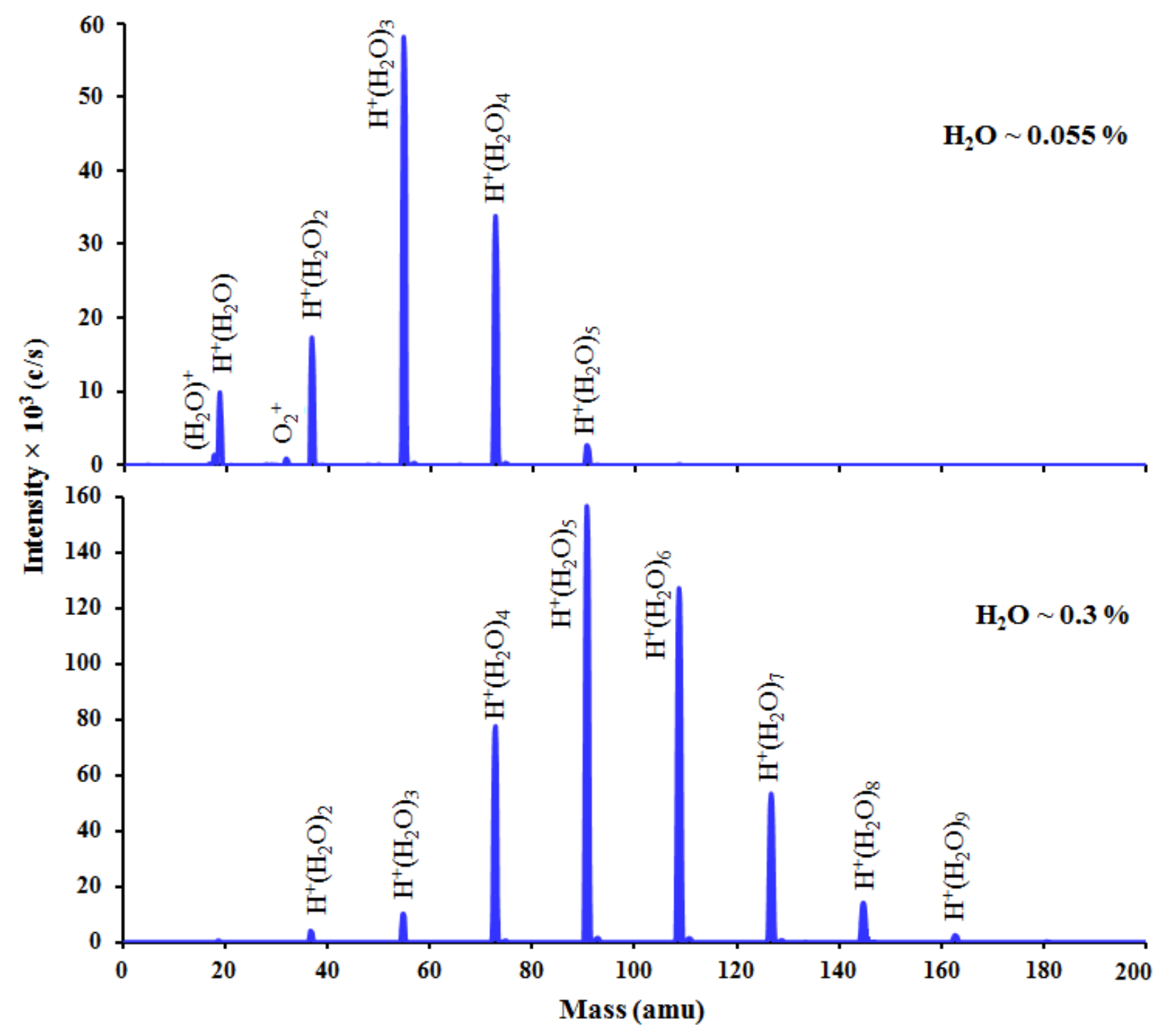

Figure 5. Positive ion mass spectra for two different water concentrations by volume $0.055 \%$ and 0.3 $\%$. Total flow rate of about $5 \mathrm{slm}$, applied power $0.3 \mathrm{~W}$, electrode separation $0.5 \mathrm{~mm}$, residence time $1.7 \mathrm{~ms}$ and frequency of $10 \mathrm{kHz}$ were used.

Figure 6 shows the relative yield $(Y(\%))$ of the most dominant negative and positive ion clusters $\mathrm{OH}^{-}\left(\mathrm{H}_{2} \mathrm{O}\right)_{n}$ and $\mathrm{H}^{+}\left(\mathrm{H}_{2} \mathrm{O}\right)_{n}$ as a function of water concentration. $\mathrm{OH}^{-}\left(\mathrm{H}_{2} \mathrm{O}\right)_{n}$ and $\mathrm{H}^{+}\left(\mathrm{H}_{2} \mathrm{O}\right)_{n}$ clusters formed $92 \%$ and $99 \%$ of the overall relative yield of negative and positive ions, respectively. Clear trends in both positive and negative ions were observed depending on cluster size. The relative yield of clusters with $n \leq 3$ decreased with increasing the water concentration and increased for $n \geq 7$. For $\mathrm{n}=4$ to 6 a gradual change in the ion yield occurred. The relative yield of these clusters increased with increasing water concentration to an optimal point and then gradually decreased as water concentration increased further. To simplify the graphs, these water clusters were not plotted in figure 6 . This behaviour could be explained by an increase in the formation of larger clusters by ion-molecule reaction processes between smaller ionic clusters and water molecules as shown in reactions R5 and R9. 


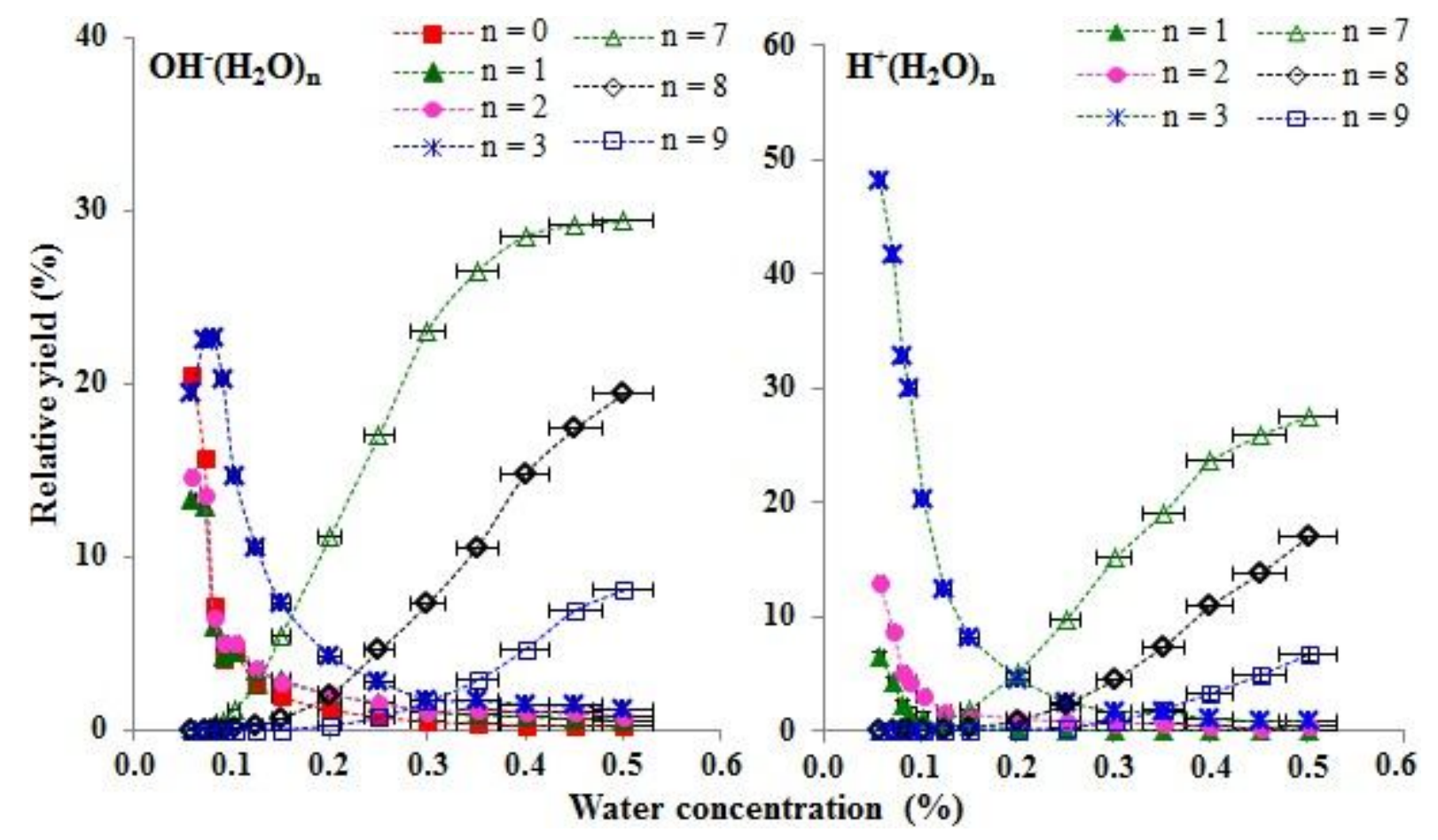

Figure 6. The relative yield of negative and positive ionic water clusters as a function of water concentration in helium. Total flow rate of about $5 \mathrm{slm}$, applied power $0.3 \mathrm{~W}$, electrodes separation 0.5 $\mathrm{mm}$, residence time $1.7 \mathrm{~ms}$, reduced electric field strength, E/N, $62 \mathrm{Td}$ and frequency of $10 \mathrm{kHz}$ were used.

\subsection{Influence of plasma residence time}

The effect of gas residence time on the formation of negative and positive ions was investigated. The residence time was controlled by changing the total gas flow rate entering the reactor. Varying the total gas flow rate from 0.8 to $5 \mathrm{slm}$ gives a residence time between 10 and $1.7 \mathrm{~ms}$, respectively. Water concentration, inter-electrode spacing and applied power were fixed to $0.3 \%, 0.5 \mathrm{~mm}$ and $0.2 \mathrm{~W}$, respectively. Figure 7 shows the effect of residence time on the intensity of $\mathrm{OH}^{-}\left(\mathrm{H}_{2} \mathrm{O}\right)_{n}$ and $\mathrm{H}^{+}\left(\mathrm{H}_{2} \mathrm{O}\right)_{n}$ clusters. Results show that increasing the residence time leads to a decrease in the relative yield of large water clusters (i.e. $n \geq 6$ ), accompanied by an increase in the relative yield of small water clusters (i.e. $\mathrm{n} \leq 4)$. In the case of $\mathrm{OH}^{-}\left(\mathrm{H}_{2} \mathrm{O}\right)_{5}$ negative ions, no significant change in the relative yield was observed. This is thought to be due to equilibrated loss and production mechanisms under the present experimental conditions. When the residence time is long, significant fragmentation of large clusters occurs; this is thought to be due to the increased number of collisions occurring. The breakdown of large clusters to smaller clusters can be represented by the following reactions [33, 38]:

$$
\begin{array}{ll}
\mathrm{OH}^{-}\left(\mathrm{H}_{2} \mathrm{O}\right)_{n}+\mathrm{M} \rightarrow \mathrm{OH}^{-}\left(\mathrm{H}_{2} \mathrm{O}\right)_{n-1}+\mathrm{H}_{2} \mathrm{O}+\mathrm{M} & k_{l 1}=f\left(T_{g}\right) \mathrm{cm}^{3} \mathrm{~s}^{-1} \\
\mathrm{H}^{+}\left(\mathrm{H}_{2} \mathrm{O}\right)_{n}+\mathrm{M} \rightarrow \mathrm{H}^{+}\left(\mathrm{H}_{2} \mathrm{O}\right)_{n-1}+\mathrm{H}_{2} \mathrm{O}+\mathrm{M} & k_{l 2}=f\left(T_{g}\right) \mathrm{cm}^{3} \mathrm{~s}^{-1}
\end{array}
$$




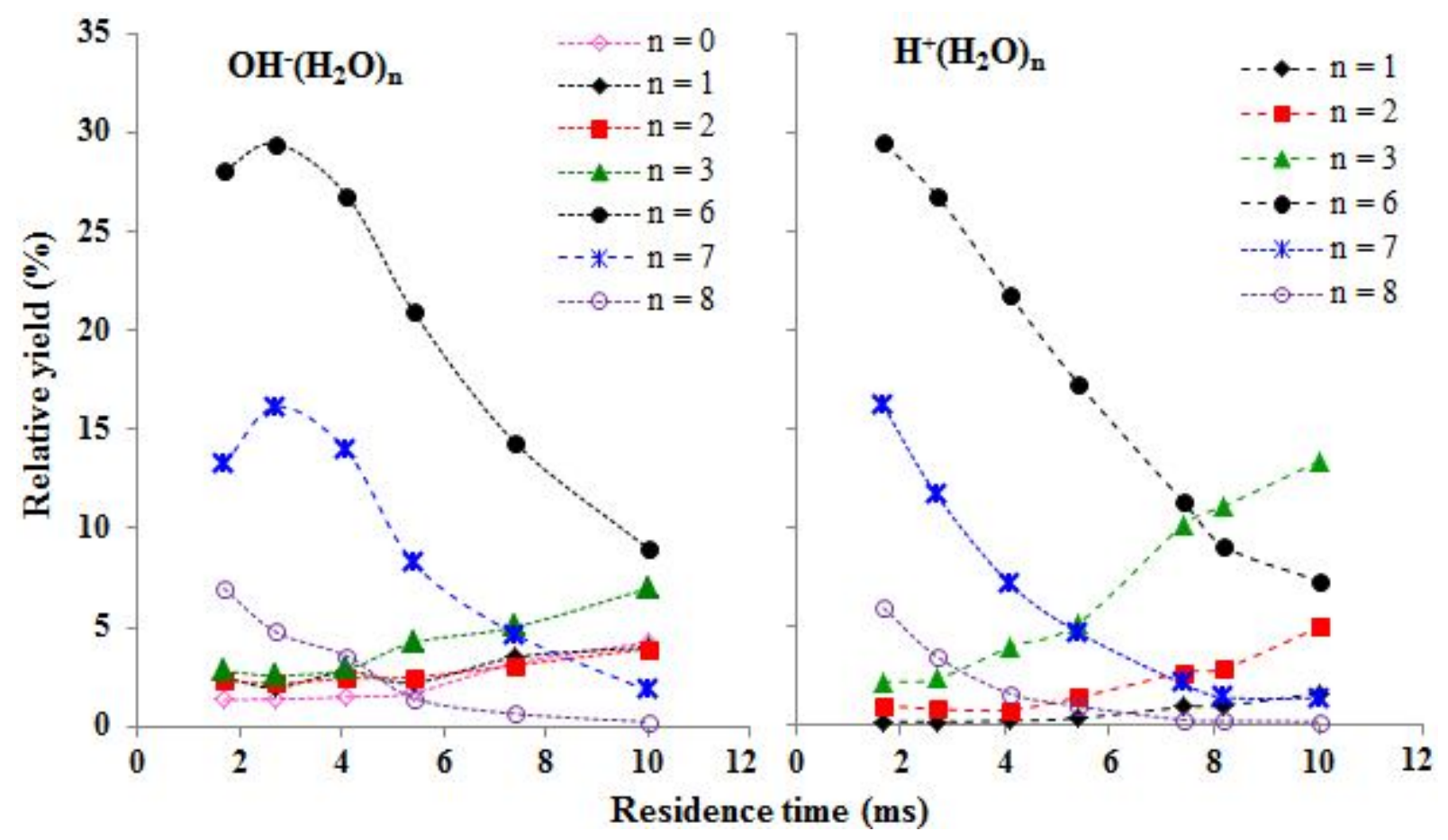

Figure 7. The relative yield of negative and positive ionic water clusters as a function of gas residence time in the plasma. Water concentration of $0.3 \%$, applied power of $0.2 \mathrm{~W}$, electrode separation $0.5 \mathrm{~mm}$,

$\mathrm{E} / \mathrm{N} 51 \mathrm{Td}$ and frequency of $10 \mathrm{kHz}$ were used.

\subsection{Influence of applied power:}

Figure 8 shows the effect of increasing the applied power on the formation of the dominant negative and positive ions in the plasma. The applied power was varied between 0.1 and $0.7 \mathrm{~W}$ giving a change in the discharge power per unit volume dissipated in the gas from 0.63 to $4.4 \mathrm{~W} \mathrm{~cm}^{-3}$, respectively. This change of the power results also in change in the reduced electric field strength, E/N, between 47 and $86 \mathrm{Td}$. Water concentration, inter-electrode spacing and residence time were fixed at $0.3 \%, 0.5 \mathrm{~mm}$ and $3.7 \mathrm{~ms}$, respectively. For negative ions, increasing the discharge power resulted in a decrease in the relative yield of large $\mathrm{OH}^{-}$containing water clusters with $\mathrm{n} \geq 6$. The relative yield of small water clusters with $\mathrm{n} \leq 5$ was not affected by the change in the applied power. The change in the intensity of positive ions as a function of applied power showed a different trend. The intensity increased with increasing the applied power to $0.25 \mathrm{~W}$, followed by negligible change with a further increase to $0.6 \mathrm{~W}$ and a decrease in the intensity of $\mathrm{H}^{+}\left(\mathrm{H}_{2} \mathrm{O}\right)_{n}$ was observed at $0.7 \mathrm{~W}$. This result did not match our expectation; we anticipated a decrease in the formation of negative and positive large ionic clusters with increased power density. Initial measurements of the gas temperature at the sampling orifice showed no change in the gas temperature as a function of power, indicating that the thermal decomposition of water clusters is not a contributing factor in this case. The chemistry of the ions that leads to these changes is not fully understood and more work still needs to be done to gain further understanding. 


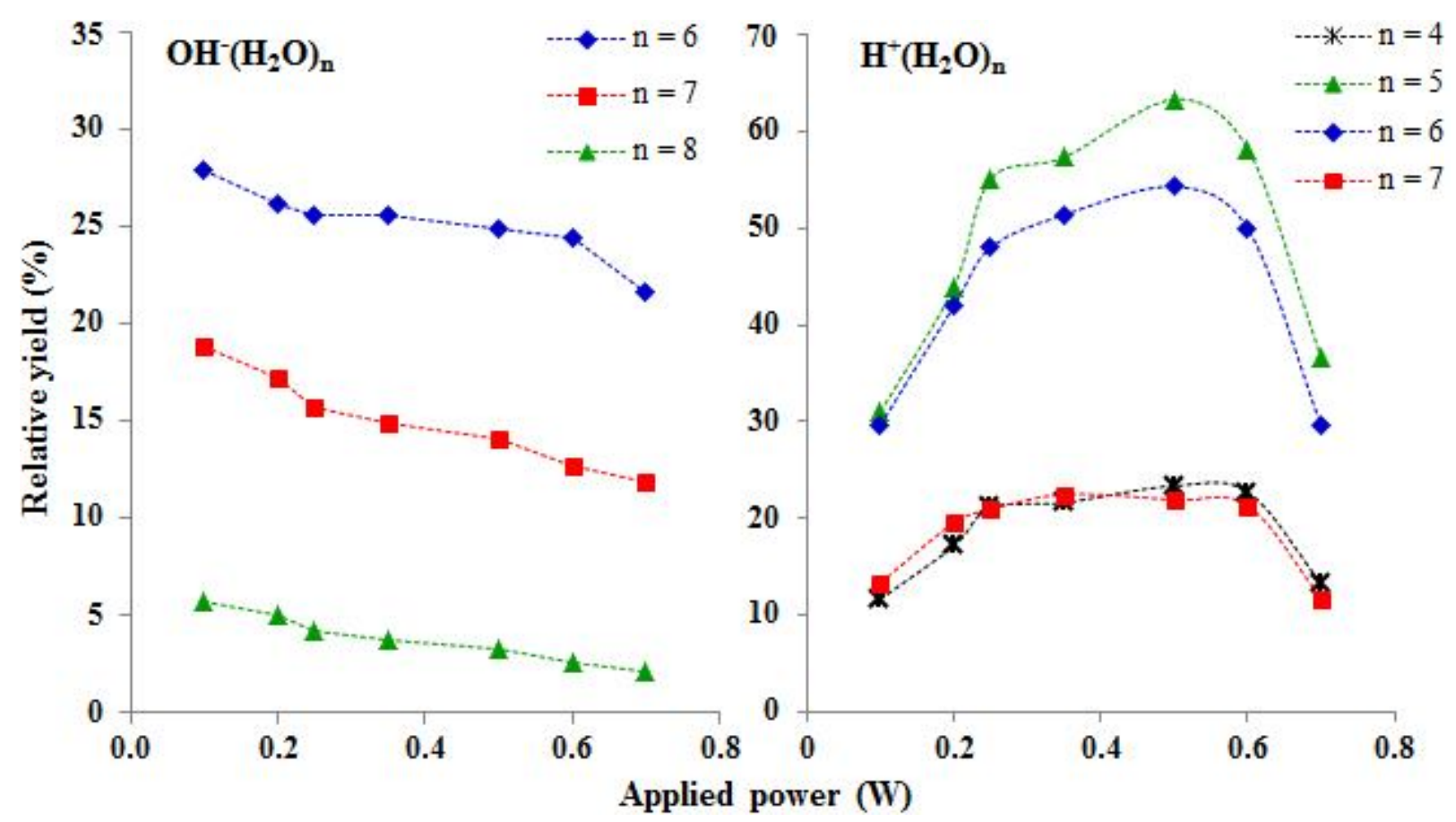

Figure 8. The relative yield of negative and positive ionic species as a function of applied power. Water concentration of $0.3 \%$, total flow rate of $2.5 \mathrm{slm}$, residence time of $3.7 \mathrm{~ms}$, electrodes gap $0.5 \mathrm{~mm}$ and frequency of $10 \mathrm{kHz}$ were used.

\subsection{Influence of inter-electrode spacing}

The effect of the inter-electrode spacing on the formation of negative and positive ions was also investigated. The spacing was varied between $0.25 \mathrm{~mm}$ and $2 \mathrm{~mm}$, while water concentration and applied power were fixed at $0.2 \%$ and $0.3 \mathrm{~W}$, respectively. Figure 9 shows a dramatic change in the relative yield of negative and positive ions as a function of inter-electrode spacing. Negative water clusters with $\mathrm{n} \leq 3$ display a sharp decrease in their relative yield when electrode spacing was increased from 0.25 to 0.75 $\mathrm{mm}$, while clusters with $\mathrm{n} \geq 4$ had a significant increase in their relative yield over the same range. Above $0.75 \mathrm{~mm}$ the relative yield of these ions did not change significantly. As for the positive ions, similar trends were observed, however, the decrease of the relative yield for $\mathrm{H}^{+}\left(\mathrm{H}_{2} \mathrm{O}\right)_{3}$ continued up to a gap of approximately $1.25 \mathrm{~mm}$. For negative ions, this can be explained by the change in residence time, power density and electric field when increasing the discharge volume. Increasing the electrode separation from $0.25 \mathrm{~mm}$ to $2 \mathrm{~mm}$ results in increasing the residence time from 1.9 to $15 \mathrm{~ms}$, decreasing the power density from 3.8 to $0.5 \mathrm{~W} \mathrm{~cm}^{-3}$ and decreasing the $\mathrm{E} / \mathrm{N}$ from 124 to $15 \mathrm{Td}$. Results presented in figures 7 and 8 showed that increasing the residence time resulted in fragmenting the large water clusters, while low power density favoured the formation of large water clusters. The reduced electric field strength is higher with smaller spacing between the electrodes. The fragmentation of large water clusters is more likely to happen with stronger electric fields, due to increased bombardment of the clusters by energetic electrons. As the reduced electric field strength decreases with increasing electrode separation, there is 
an increase in the formation of heavier ions [34]. Increasing the electrode gap causes an opposition between the effect of increasing the residence time and that of decreasing the power density and the electric field. The opposing effects tend to balance each other, and lead to no change in the intensity of ions with an inter-electrode spacing varying between 0.75 and $2 \mathrm{~mm}$. The change of the intensity of positive ions as a function of the inter-electrode spacing is similar to that of the negative ions.

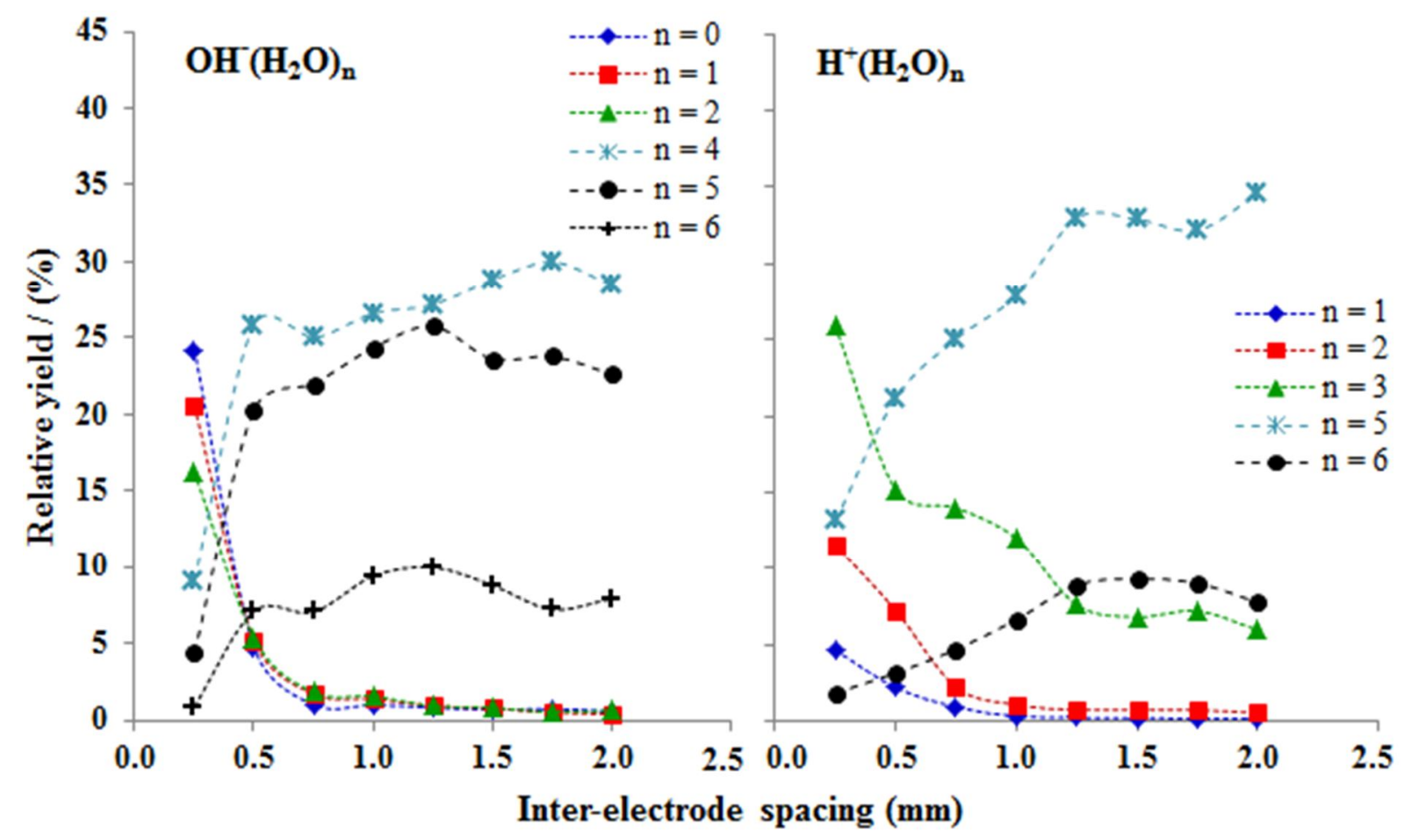

Figure 9. The relative yield of negative and positive ionic water clusters as a function of electrodes separation. Water concentration of $0.2 \%$, total flow rate of $2.5 \mathrm{slm}$, applied power $0.3 \mathrm{~W}$ and frequency of $10 \mathrm{kHz}$ were used.

\section{Conclusions:}

Negative and positive ions generated in the active plasma of atmospheric pressure parallel plate DBD reactor have been identified. The influence of several operating conditions of water concentration, residence time, applied power and inter-electrode spacing on the chemistry of ionic species in helium and water gas mixture were investigated. The dominant negative ions formed in the active discharge were $\mathrm{O}^{-}\left(\mathrm{H}_{2} \mathrm{O}\right)_{n}$ and $\mathrm{OH}^{-}\left(\mathrm{H}_{2} \mathrm{O}\right)_{n}$, while the main positive ion was $\mathrm{H}^{+}\left(\mathrm{H}_{2} \mathrm{O}\right)_{n}$. Results revealed that the effect of operating conditions differs according to cluster size. The formation of large mass ionic water clusters increased with increasing the water vapour concentration in the discharge as a result of ionmolecule reactions between small ions and water molecules. An increase in the fragmentation of large water clusters into smaller clusters was observed when the residence time of the species in the discharge region increased. The relative yield of large $\mathrm{OH}^{-}\left(\mathrm{H}_{2} \mathrm{O}\right)_{n}$ clusters decreased with increasing the applied 
power, while more work is still required to gain further understanding of the positive ions response to applied power. At electrode spacing greater than $0.75 \mathrm{~mm}$, there was no change in the intensity of ionic species due to the contradictory effect of the residence time and power density. This investigation is the first detailed in-situ analysis for an atmospheric-pressure DBD plasma using mass spectrometry. The comprehensive study of the effects of process parameters on the plasma chemistry has given greater insight into the formation of water clusters in a helium dielectric barrier discharge, and demonstrates the effectiveness of the measurement technique for such studies. Future work is directed towards investigating the ionic chemistry produced in atmospheric pressure nitrogen plasma in the presence of precursors.

\section{Acknowledgment:}

The authors would like to thank EPSRC for funding the project. Thanks to our industrial partners, Innovia Films Ltd. Also thank you to Mr Alan Roby for his technical support.

\section{References:}

[1] Ulrich Kogelschatz B E, Walter Egli 1999 From ozone generators to flat television screens: history and future potential of dielectric-barrier discharges Pure Appl. Chem. 71 1819-28

[2] Teranishi K, Shimomura N, Suzuki S and Itoh H 2009 Development of dielectric barrier discharge-type ozone generator constructed with piezoelectric transformers: effect of dielectric electrode materials on ozone generation Plasma Sources Sci. Technol. 18045011

[3] Chen H L, Lee H M and Chen S H 2008 Review of Packed-Bed Plasma Reactor for Ozone Generation and Air Pollution Control Industrial \& Engineering Chemistry Research 47 2122-30

[4] Laroussi M 1996 Sterilization of contaminated matter with an atmospheric pressure plasma IEEE Trans. Plasma Sci. 24 1188-91

[5] Fridman G, Friedman G, Gutsol A, Shekhter A B, Vasilets V N and Fridman A 2008 Applied Plasma Medicine Plasma Processes Polym. 5 503-33

[6] Stoffels E 2006 Gas plasmas in biology and medicine J. Phys. D: Appl. Phys. 39

[7] Kim H H 2004 Non-thermal Plasma Processing for Air Pollution Control: A Historical Review, Current Issues, and Future Prospects Plasma Processes Polym. 191-110

[8] Abd Allah Z, Whitehead J C and Martin P 2014 Remediation of Dichloromethane $\left(\mathrm{CH}_{2} \mathrm{Cl}_{2}\right)$ Using Non-thermal, Atmospheric Pressure Plasma Generated in a Packed-Bed Reactor Environ. Sci. Technol. 48 558-65

[9] Oda T 2003 Non-thermal plasma processing for environmental protection: decomposition of dilute VOCs in air Electrostatics $\mathbf{5 7} 293-311$

[10] Kogelschatz U 2003 Dielectric-barrier Discharges: Their History, Discharge Physics, and Industrial Applications Plasma Chem. Plasma Process. 23

[11] Fridman A 2008 Plasma chemistry: Cambridge University Press)

[12] Lieberman M and Lichtenberg A 1994 Principles of plasma discharges and materials processing: Wiley-Interscience)

[13] Massines F, Gherardi N, Naudé N and Ségur P 2005 Glow and Townsend dielectric barrier discharge in various atmosphere Plasma Phys. Controlled Fusion 47 B577

[14] Vinogradov I S, M. ; Lunk, A. 2007 Spectroscopic Diagnostics of DBD Remote Plasma in Ar/Fluorocarbon Mixtures-Correlation Between Plasma Parameters and Thin Film Properties Plasma Processes Polym. 4 S797-S800

[15] Niu J, Liu D and Wu Y 2011 Large-area and uniform surface modification of polymers by barrier discharge plasmas Surf. Coat. Technol. 205 3434-7 
[16] Kogelschatz U 2002 Filamentary, patterned, and diffuse barrier discharges IEEE Trans. Plasma Sci. 30 1400-8

[17] Gherardi N and Massines F 2001 Mechanisms Controlling the Transition from Glow Silent Discharge to Streamer Discharge in Nitrogen IEEE Transaction on Plasma Science 29

[18] Kim Y, Cha M S, Shin W-H and Song Y-H 2003 Characteristics of Dielectric Barrier Glow Discharges with a Law- Frequency Generator in Nitrogen Journal Of the Korean Physical Society $43732-7$

[19] Fridman A and Kennedy L 2004 Plasma Physics and Engineering: Taylor and Francis)

[20] Chirokov A, Gutsol A and Fridman A 2005 Atmospheric pressure plasma of dielectric barrier discharges Pure Appl. Chem. 74 447-95

[21] Chiper A S, Chen W, Stamate E, Chiper A S, Chen W and Stamate E 2009 Diagnostics of DBD Plasma Produced Inside a Closed Package. In: Proceedings ISPC 19 (online), ed V Schulz-von der Gathen

[22] Schulze J, Schüngel E and Czarnetzki U 2009 The electrical asymmetry effect in capacitively coupled radio frequency discharges - measurements of dc self bias, ion energy and ion flux $J$. Phys. D: Appl. Phys. 42092005

[23] Barton D, Bradley J W, Steele D A and Short R D 1999 Investigating Radio Frequency Plasmas Used for the Modification of Polymer Surfaces J. Phys. Chem. B 103 4423-30

[24] O'Toole L and D. Short R 1997 An investigation of the mechanisms of plasma polymerisation of allyl alcohol J. Chem. Soc., Faraday Trans. 93 1141-5

[25] Oh J-S, Aranda-Gonzalvo Y and Bradley J W 2011 Time-resolved mass spectroscopic studies of an atmospheric-pressure helium microplasma jet J. Phys. D: Appl. Phys. 44365202

[26] McKay K, Oh J-S, Walsh J L and Bradley J W 2013 Mass spectrometric diagnosis of an atmospheric pressure helium microplasma jet J. Phys. D: Appl. Phys. 46464018

[27] Bruggeman P, Iza F, Lauwers D and Gonzalvo Y A 2010 Mass spectrometry study of positive and negative ions in a capacitively coupled atmospheric pressure J. Phys. D: Appl. Phys. 43 012003

[28] Hołub M 2012 On the measurement of plasma power in atmospheric pressure DBD plasma reactors INT J Appl Electrom 39 81-7

[29] Martens T, Bogaerts A, Brok W J M and Dijk J V 2008 The dominant role of impurities in the composition of high pressure noble gas plasmas Appl. Phys. Lett. 92 -

[30] Klee S, Derpmann V, Wißdorf W, Klopotowski S, Kersten H, Brockmann K, Benter T, Albrecht S, Bruins A, Dousty F, Kauppila T, Kostiainen R, O'Brien R, Robb D and Syage J 2014 Are Clusters Important in Understanding the Mechanisms in Atmospheric Pressure Ionization? Part 1: Reagent Ion Generation and Chemical Control of Ion Populations J. Am. Soc. Mass. Spectrom. 25 1310-21

[31] Zavilopulo A N, Chipev F F and Shpenik O B 2005 Ionization of nitrogen, oxygen, water, and carbon dioxide molecules by near-threshold electron impact Technical Physics 50 402-7

[32] Sakiyama Y, Graves D B, Chang H-W, Shimizu T and Morfill G E 2012 Plasma chemistry model of surface microdischarge in humid air and dynamics of reactive neutral species J. Phys. D: Appl. Phys. 45425201

[33] Liu D X, Bruggeman P, Iza F, Rong M Z and Kong M G 2010 Global model of low-temperature atmospheric-pressure $\mathrm{He}+\mathrm{H}_{2} \mathrm{O}$ plasmas Plasma Sources Sci. Technol. 19025018

[34] Skalny J D, Orszagh J, Mason N J, Rees J A, Aranda-Gonzalvo Y and Whitmore T D 2008 Mass spectrometric study of negative ions extracted from point to plane negative corona discharge in ambient air at atmospheric pressure Int. J. Mass spectrom. 272 12-21

[35] Cody R B, Laramée J A and Durst H D 2005 Versatile New Ion Source for the Analysis of Materials in Open Air under Ambient Conditions Anal. Chem. 77 2297-302

[36] Chiu Y M, Hung C-T, Hwang F-N, Chiang M H, Wu J-S and Chen S H 2011 Effect of plasma chemistry on the simulation of helium atmospheric-pressure plasmas Computer Physics Communications Special Edition for Conference on Computational Physics Kaohsiung, Taiwan, Dec 15-19, 2009182

[37] Murakami T, Niemi K, Gans T, O'Connell D and Graham W G 2013 Chemical kinetics and reactive species in atmospheric pressure helium-oxygen plasmas with humid-air impurities Plasma Sources Sci. Technol. 22015003 
[38] McKay K, Walsh J L and Bradley J W 2013 Observations of ionic species produced in an atmospheric pressure pulse-modulated RF plasma needle Plasma Sources Sci. Technol. 22 035005 